\title{
ESCRITOS SOBRE UM CORPO: A LETRA DE SCHOLEM COMO SIGNO DE BENJAMIN
}

Para Tereza de Castro Callado

Arminda Serpa ${ }^{1}$

\begin{abstract}
RESUMO
Em Walter Benjamin: a história de uma amizade, a escritura encontra-se no centro do corpo, paisagem de afeto e beleza. Nas memórias sonoras da letra de Scholem uma poética é instaurada, por mais que haja a tentativa de fidelidade ao real. Benjamin torna-se signo. Nosso estudo procurou apreender de que forma a letra marca a eroticidade da linguagem e revela a essência da Philosofia como sabedoria e comunhão. As leituras de Lísis de Platão e dos diálogos de Borges também foram essenciais para compreender a amizade como possibilidade criativa, ou seja, como prática do significante que revela o erótico da letra, fazendo assim surgir o corpo como lugar de leituras e a escritura como ciência das fruições.
\end{abstract}

Palavras-chave: Benjamin. Scholem. Amizade. Escritura.

\section{WRITTEN ON A BODY: SCHOLEM'S LETTER AS A SIGN OF BENJAMIN}

\begin{abstract}
In Walter Benjamin: the story of a friendship, the deed is located in the center of the body, a landscape of care and beauty. In the sound memories of the letter of Scholem, a poetics is established, and, although an effort can be noticed to keep it loyal to the real. Benjamin becomes sign. Our study sought to grasp how the letter marks the eroticism of language and reveals the Philosofia as the essence of wisdow communion. Reading on Lysis Platos and Borges' dialogues were also essential to understand friendship as creative possibility, in other words, has practice of the signifier which reveals the erotic letter, thus making the body appear as a place of reading and writing as a science of fruitions.
\end{abstract}

Keywords: Benjamin. Scholem. Friendship. Letter.

\section{A palavra incorporada: a letra ao pé da letra}

Escrever está no centro do corpo, eis a lição de Scholem. A fala de Scholem é um rumor (rumor da língua como diria Barthes) que secreta um corpo: o corpo de Benjamim.

\footnotetext{
${ }^{1}$ Arminda Serpa é Mestra em Literatura Brasileira pela Universidade Federal do Ceará e Professora de Literatura da Universidade Estadual do Ceará.
} 
O corpo de Benjamin se transforma em som, som que rasga a folha de papel ou nossos ouvidos. Transforma-se também em imagem. Uma imagem que irrompe diante dos nossos olhos. Imagem dos afetos, dos fulgores, da paisagem. Paisagem afetiva configurada por conflitos, desejo, amizade, sonhos, pela beleza. "A beleza salvará o mundo". Segundo Todorov, a frase de Dostoievski nunca foi tão atual:

\begin{abstract}
Pois é justamente quando tantas coisas vão mal em torno de nós que é necessário falar da beleza do planeta e do humano que o habita. É preciso entender: a palavra 'beleza' recebe aqui um sentido amplo que nem sempre é admitido no nosso uso comum. Esse sentido não implica que se passe a vida a admirar os pores do sol ou luares nem que se aplique a enriquecê-la com alguns elementos decorativos comprados em loja. Trata-se mais da tentativa de ordenar a vida de maneira que a consciência individual a julgue harmoniosa de modo que os diferentes ingredientes, vida social, profissional, íntima e material formem um todo inteligível. ${ }^{2}$
\end{abstract}

A palavra incorporada na beleza, ou seja, como entendimento do corpo (que já não é, tornou-se som, letra) é o objetivo de Scholem ao compor o texto "Walter Benjamin: a história de uma amizade" (1989). O texto é um relato em primeira pessoa (assemelha-se a um diário). Também poderíamos dizer que parece um memorial. Sendo assim de que a Scholem deve recordar-se? De Benjamin? Sim. E de si mesmo. De si mesmo através de Benjamin. Benjamin, signo de recordação e do esquecimento. Pois escrever é registrar para não esquecer. Ele escreve para que a experiência da amizade possa ser absorvida, sorvida.

Scholem deseja evitar a ausência física do amigo através da letra porque na letra há uma aproximação das linhas do tempo, ou seja, há uma concentração no presente (presente da nossa leitura) de todos os tempos imagináveis a desenrolar-se para sempre. Partitura dos "agoras".

Scholem escreve a história da amizade e o livro não é como pode parecer, à primeira vista, um objeto rápido de leitura. Ele dissimula, no sentido de encobrir/ ser um palimpsesto, uma época e alguém. E o verbo dissimular aqui liga-se ao simulacro. O real, como assinalou Lacan, é impossível. Como apreender Benjamin, senão como signo de Scholem? Scholem trabalha com a materialidade do signo e não com a carne viva do corpo de Benjamin. Ele trabalha com a letra.

\footnotetext{
${ }^{2}$ TODOROV, A Beleza salvará o mundo, 2011, p. 13
} 
O livro tem como referencial a história de uma amizade, mas há aí uma dobra da escrita, pois o livro também é uma auto-reflexão de Scholem sobre o relacionamento que o unia a um outro. Um homem fascinante e em momentos consideráveis, Scholem registra que Benjamin era um homem de personalidade atraente.

Assim, quem sabe, Benjamim é recolhido como um sonho. Uma constelação de textos na mão e nos olhos do amigo. Scholem trabalha com a dura matéria da língua, a suave lâmina da matéria (repleta de sons, sentidos e não sentidos). Matéria paradoxal, de insustentável leveza.

O texto que te dou é "paisagem" nos diz Clarice Lispector em Água Viva (2008:31) e o mesmo nos poderia dizer Scholem:

\begin{abstract}
Este texto que te dou não é para ser visto de perto: ganha sua secreta redondez antes invisível quando é visto de um avião em alto voo. Então adivinha-se o jogo das ilhas e vêem-se canais e mares. Entende-me: uma onomatopéia, convulsão da linguagem. Transmitote não uma história, mas apenas palavras que vivem do som. ${ }^{3}$
\end{abstract}

Scholem não inicia a história da amizade com o "era uma vez", mas com um prefácio no qual reivindica a autenticidade do escrito, mesmo assinalando imprecisões das falas, dos gestos, desbotamentos da memória e também a inserção de si no contado:

"o que posso oferecer aqui é a historia de nossa amizade e meu
testemunho sobre o homem Walter Benjamin, tal como o conheci. É
próprio do tema que aqui e ali, sobretudo no começo e em algumas
notas e cartas, eu tenha que falar de mim mesmo, na medida em que
for necessário para a compreensão desta amizade".

Preocupado com a tarefa de transmitir uma autêntica versão sobre o parceiro, após trinta e cinco anos da morte deste, ele esclarece:

Um tal escritor de memórias vai esperar que se lhe pergunte - e ainda mais num caso tão carregado de polêmicas quando o de Walter Benjamin - com que direito ele pode relatar, parafrasear e interpretar fatos que nem sempre são amparados por um material comprobatório direto. Decerto, muito do que é relatado aqui baseia-se em notas de diário, em outras anotações e em muitas cartas que pude utilizar diretamente ou para fins de comprovação. Todavia, para muitos itens, não pode o memorialista, pela natureza das coisas, exigir outro crédito senão, como ele mesmo deve crer, o de sua própria confiabilidade e integridade pessoalmente comprovadas. A quem

\footnotetext{
${ }^{3}$ LISPECTOR. Água viva, 2008, p. 31

${ }^{4}$ SCHOLEM, Walter Benjamin: história de uma amizade, 1989, p. 8.
} 
No entanto, as memórias se transformarão em uma paisagem sonora de beleza e verdade para os que estão livres do preconceito em relação ao fato de que elas se esteiem em "muitos anos de estreito relacionamento" ${ }^{6}$ e para os que sabem conduzir com alegria e liberdade os signos da interpretação.

Benjamin é alvo da língua. A língua é uma impostura. Porém, Scholem deseja atingir a língua sem impostura. É isso o que o texto dele quer. Para Scholem, não há metáforas. Uma coisa é ou não é. Com sua visão de historiador esquece que a pele virou palavra. Ele esquece sonambulamente 0 rumor de sua fala, o peso da palavra, da metáfora.

Todo escrito encontra-se atravessado pela ficção, por mais que busque o alem da linguagem, o impronunciável, o real. Não se pode acreditar assim que o nome Benjamin seja o próprio Benjamin, com sua singularidade, corporeidade, em sua matéria bruta. Portanto, Benjamin torna-se signo de Scholem.

Para Lacan ${ }^{7}$ a letra é ainda mais elementar que o significante, ela se reporta ao escrito e ao que há de mais fundamental no escrito, em sua redução ao puro traço, à pura inscrição, à sulcagem da superfície/ corpo sobre o qual se escreve e se inscreve um sujeito. A letra marca. Marca a diferença entre a palavra e a coisa. Há um espaço erógeno nas palavras. Entre elas, não? $O$ traço da letra é um traço físico.

\section{De como me aproximei do texto}

Assim me aproximei do texto de Scholem, através da leitura de Lísis de Platão. Há em Lísis, a "cena-fulgor" e sempre atraente de Sócrates que proclamava reconhecer, à primeira vista, quem ama e quem é amado e o que está em jogo quando amamos pois quando amamos é em vista de algo, de algo que é amigo. $O$ desejo é a causa da amizade.

\footnotetext{
${ }^{5}$ Idem, ibidem, p. 8.

${ }^{6}$ SCHOLEM, Walter Benjamin: História de uma amizade, Opus cit, p. 8.

${ }^{7}$ LACAN. Escritos, 1998.
} 
O desejo (epithymia), por sua vez, nasce da sensação de carência (endeia), de algo que nos falta, algo afim a nós (oikeion), algo de que nos sentimos privados. Estas são idéias fundamentais em Lísis.

A amizade é definida por Sócrates como o sumo bem:

\begin{abstract}
Sucede que, desde criança, desejo possuir uma coisa. Como outros desejam outras. De fato, uns desejam adquirir cavalos. Outros, ouro. Outros, honrarias. Pela minha parte diante de tudo isso fico indiferente. Mas perante a aquisição de amigos, sinto grande ardor, e preferia encontrar um bom amigo a possuir a mais bela codorna do mundo, ou o mais belo galo, ou até, por Zeus, é verdade, um cavalo ou um cão, que mais facilmente eu aceitaria um amigo do que o ouro de Dario, mais facilmente até que Dario em pessoa, tal é a minha ânsia de ter amigos. ${ }^{8}$
\end{abstract}

Há em Lísis, um dialogo que acentua, por seu contexto de fala, o valor etimológico da palavra philosofia:

Nem há amigos de cavalos, se os cavalos não lhes retribuírem. Nem amigos de codornas, nem sequer amigos de cães, ou amigos de vinho, amigos de ginástica ou amigos de sabedoria, a não ser que, em troca, a sabedoria os ame ${ }^{9}$

Quem é o amigo? Pergunta essencial do texto de Platão. E o texto ressalta a marca, o sinal que configura o amado como sendo o philos. Como se caracteriza o philos? Como ele age? Lísis gira em torno desses questionamentos, se não há dedicação, como haverá amizade? "de nenhum modo" (1995:50). Se existe alguém e tudo para esse alguém lhe advêm de si próprio, ele não sente necessidade de amar. Pois faz parte da essência da philia uma permuta recíproca. Portanto: "o que de nada necessita, a nada se dedica" (1995:50).

Com efeito, não são amigos os que não se tiverem em grande conta, não se apreciarem. A causa, portanto, da amizade, é o desejo. "O que deseja é amigo daquilo que deseja, e isso sempre que deseja”. ${ }^{10}$ Então, quando alguém deseja, "deseja aquilo de que se sente privado..." ${ }^{11}$. Além da falta, outro traço da philia é a afinidade. Certamente, ninguém sentiria desejo, ou amor, ou

\footnotetext{
${ }^{8}$ Platão. Lísis, 1995, p. 45 e 46

${ }^{9}$ Idem, ibidem, p. 47.

${ }^{10}$ Idem, ibidem, p. 60

${ }^{11}$ Idem, ibidem, p. 60
} 
amizade, "se por acaso não fosse em algo afim do amado, quanto à alma ou a qualquer traço da alma, do caráter ou da figura". ${ }^{12}$

A essência da amizade é a comunhão. É inevitável o amor por aquele ou aquela que, por natureza, se mostra afim de nós. Borges ${ }^{13}$ incluía a amizade como possibilidade criativa, ou seja, a amizade também era elemento essencial de uma poética. Para ele, a amizade, entre Platão e Sócrates representava o opus classicus. Quanto a este aspecto, lembra que Jaspers afirmava que a filosofia platônica se funda nesse vinculo pessoal de toda a vida com Sócrates, e que o central dessa filosofia não é nem a natureza, nem o universo, nem o homem, nem nenhuma proposição, mas tudo isso em função dessa amizade.

Borges assinala que "os diálogos correspondem ou surgem da nostalgia de Platão por Sócrates, quer dizer Sócrates morre e Platão finge que ele continua vivendo, e que continua discutindo diversos assuntos" 14 E ele enfatiza: "E Platão, apesar da morte corporal de Sócrates, continua fingindo ou sonhando que Sócrates existe" 15 E isso, para Borges, implicaria que nas origens da filosofia ocidental esteve o grande sentimento da amizade e da ideia de morte e que certa linha do pensamento pode prosseguir na mente dos discípulos depois da morte corporal do mestre. Depois isso, ou seja, a linha de transmissão, o anel, a tocha continuam em pessoas que não conheceram o mestre pessoalmente. Nisso haveria uma espécie de comunidade espiritual.

A imagem do amigo, prossegue Borges, talvez seja mais forte após a morte. Pois "enquanto uma pessoa vive, ela está mudando, e é inapreensível. Por outro lado, quando morre, ela já tem a tranqüilidade de uma fotografia, de uma imagem fixa" 16

\section{Nosso percurso chega agora ao signo da eroticidade}

Roland Barthes, ao refletir sobre a conversa, declara:

A linguagem é uma pele: esfrego minha linguagem no outro. É como se eu tivesse palavras ao invés de dedos, ou dedo nas pontas das palavras. Minha linguagem treme de desejo. A emoção de um duplo contacto: de um lado, toda uma atividade do discurso vem,

\footnotetext{
12 Idem, ibidem, p. 60

${ }^{13}$ BORGES, Sobre a amizade e outros diálogos, 2009.

${ }^{14}$ Idem, ibidem, p. 131.

${ }^{15}$ Idem, ibidem, p. 131

${ }^{16}$ Idem, ibidem, p. 133.
} 
discretamente, indiretamente colocar em evidência um significado único que é 'eu te desejo', e libertá-lo, alimentá-lo e ramificá-lo, fazêlo explodir (a linguagem goza de se tocar a si mesma); por outro lado, envolvo o outro nas minhas palavras, eu o acaricio, o roço, prolongo esse roçar, me esforço em fazer durar o comentário ao qual submeto a relação $(1991: 64) .{ }^{13}$

A sensualidade propaga-se na linguagem. Esta, por sua vez, é a única presença do corpo que se tornou signo. Letra e som se fundem alcançando o cerne da linguagem, movimento de gozo: letra se fundindo em som, som se fundindo em letra. Uma voz que alcança o ápice da enunciação. Voz potente de signos.

E será que não compreendemos o que ali se enuncia? Por que no momento do jorro dos sons, das letras, às vezes, não estamos presentes? Talvez porque esse percurso pela libido da escrita seja de difícil acesso.

Enunciar é erotizar. A poética do significante revela o erótico da letra. $\mathrm{O}$ corpo surge como lugar de leitura. Barthes afirmará: "a escritura é isto; a ciência das fruições da linguagem, seu kama-sutra" 18

Vejamos alguns instantâneos de Benjamim, por Scholem, o momento do primeiro olhar: "antes de conhecer Benjamim pessoalmente, vi-o pela primeira vez no outono de 1913, num salão em cima do Café Tiergarten, em Berlim" ${ }^{19}$. A descrição minuciosa dos traços:

\begin{abstract}
"Benjamim não era o que se poderia chamar de bonito, mas impressionava com a sua fronte extraordinariamente pura e alta. Sobre a fronte, trazia cabelos castanho-escuros, espessos, bastante altos, ligeiramente ondulados e difíceis de arrumar, como permaneceram, mais tarde ao encanecer, até o fim. A voz bonita era melodiosa e fácil de gravar na memória (...) de estatura mediana, muito esbelto naquele tempo e durante os anos seguintes, vestia-se de maneira estudadamente discreta e mantinha, em geral, o corpo levemente curvado para frente. Não creio tê-lo visto algum dia ereto e com a cabeça erguida. Seu passo tinha algo de inequívoco, deliberado e tateante, o que se devia porventura à sua miopia. (...) Sob a testa percebiam-se logo os seus grossos óculos, que tirava amiudamente na conversa, revelando os expressivos olhos azulescuros. O nariz era regular (...), e a boca, cheia e sensual.. ${ }^{20}$
\end{abstract}

Benjamin é aquele a quem Scholem soletra. Um homem só, letra. Só letra.

\footnotetext{
${ }^{17}$ BARTHES, Fragmento de um discurso amoroso, 1991, p. 64

${ }^{18}$ BARTHES, O Prazer do texto, 1999, p.11

${ }^{19}$ SCHOLEM, Walter Benjamin: A história de uma amizade, Opus cit., p. 11.

${ }^{20}$ KONDER. Walter Benjamin: O marxismo da melancolia, 1989, p. 16 e 17
} 


\section{REFERÊNCIAS}

BARTHES, Roland. O prazer do texto. São Paulo: Perspectiva, 1999. . O rumor da língua. São Paulo: Brasiliense, 1988.

. Fragmentos de um discurso amoroso. Rio de Janeiro: Francisco Alves, 1991.

BORGES, Jorge Luis. Sobre a amizade e outros diálogos. São Paulo: Hedra, 2009.

KONDER, Leandro. Walter Benjamin: o marxismo da melancolia. Rio de Janeiro: Campus, 1989.

LACAN, Jacques. Escritos. Rio de Janeiro: Jorge Zahar, 1998.

. Outros Escritos. Rio de Janeiro: Jorge Zahar, 2003.

PLATÃO. Lísis. Introdução, versão e notas de Francisco de Oliveira - Brasília: Universidade de Brasília, 1995.

LISPECTOR, Clarice. Água Viva. São Paulo: Prumo, 2008.

ROAUNET, Sergio Paulo. Édipo e o anjo: itinerários freudianos em Walter Benjamim. Rio de Janeiro: Tempo Brasileiro, 1990.

SCHOLEM, Gershom. Walter Benjamim: A história de uma amizade. São Paulo: Perspectiva, 1989.

TODOROV, Tzevetan. A beleza salvará o mundo: Wilde, Rilke, Tsvetaeva: os aventureiros do absoluto. Rio de Janeiro: DIFEL, 2011. 